\title{
Emerging Treatment Options in Atopic Dermatitis: Systemic Therapies
}

\author{
Uffe Nygaard Christian Vestergaard Mette Deleuran \\ Department of Dermatology and Venereology, Aarhus University Hospital, Aarhus, Denmark
}

\begin{abstract}
Keywords
Atopic dermatitis · Systemic treatment - Dupilumab .

Tralokinumab · Lebrikizumab · Ustekinumab .

Nemolizumab - Tezepelumab - OX40 ligand antagonist .

Anti-lgE therapy · Janus kinase inhibitors - Baricitinib .

Tofacitinib - Apremilast - Phosphodiesterase-4 inhibitors .

$\mathrm{SH} 2$-containing inositol-5'-phosphatase 1 activators
\end{abstract}

\begin{abstract}
The pathogenesis of atopic dermatitis (AD) is multifactorial and intricate, and the clinical presentation of the condition varies greatly. Symptoms and severity depend on individual trigger factors and stage of the disease. The majority of $A D$ patients are sufficiently treated with emollients in combination with existing topical or systemic therapies. Yet treatment failure with existing drugs and treatment options can be a significant clinical problem. New treatments are under development, and the majority of these new drugs focus on targeting a skewed immune response in AD. Novel therapeutic approaches, which target the pathways involved in the pathogenesis of $A D$, may provide a potentially more effective and less harmful approach to systemic therapy. These pharmaceutical agents are designed to narrowly modify or directly block a specific cellular signal or pro-inflammatory pathway. We review systemic drugs in the pipe-
\end{abstract}

\section{KARGER}

(c) 2018 S. Karger AG, Basel

E-Mail karger@karger.com

www.karger.com/drm line for AD. To make the review as current and pertinent as possible, we selected to focus on AD-related therapies available in the clinicaltrials.gov database with a first received date after January 1, 2014, up until May 31, 2017. We excluded therapies that could be categorized as either traditional Chinese medicine, herbal medicine, probiotics, histamine/leukotriene blockers, immuno-adsorption, or immunostimulants.

(c) 2018 S. Karger AG, Basel

\section{Introduction}

Atopic dermatitis (AD) is the most common inflammatory dermatological disorder. It is chronic or chronically relapsing, and characterized by intense pruritus and dry skin. While the incidence of AD has now stagnated, the dramatic increase during the last few decades has resulted in $10-25 \%$ of children and $2-8 \%$ of adults in affluent nations being affected. Of all patients affected, up to one quarter fall in the category of moderate to severe disease [1-3]. Approximately one third of patients carry the disease into adulthood, hence for some the disease is lifelong. The underlying aetiopathogenesis of $\mathrm{AD}$ is multifaceted with the key elements being an impaired skin barrier and a dysregulated immune response, together fa- 
cilitating the pathophysiological mechanisms driving the disease. The risk modifiers for $\mathrm{AD}$ are many, e.g. filaggrin null mutations, family predisposition and domestic hard water, with new ones being unveiled continuously [4-6]. Moreover, the growing list of associated comorbidities including cardiovascular disease, attention deficit and hyperactivity disorder, lymphoma, and others gives rise to additional concern demanding early intervention and novel disease-modifying strategies [7-11]. Chronic, moderate to severe $\mathrm{AD}$ is a debilitating condition with a harmful socio-economic impact on the patient, the family, and the society as a whole. In a minority of patients with $\mathrm{AD}$, the severe pruritus, time-costly skin care routines, associated sleep disturbance and poor quality of life make the disease intolerable.

\section{Established Therapies}

Various treatment approaches exist for alleviating the disease, including hydration and restoration of the skin barrier with the use of emollients, avoiding typical AD triggers, specific behavioural approaches to reduce scratching, antibacterial measures, and topical and/or systemic anti-inflammatory drugs [12,13]. Development of new topical and systemic therapies has been lacking. Furthermore, much of the evidence for systemic treatment modalities used in $\mathrm{AD}$ is restricted to casuistic reports, case series or retrospective studies. In mild to moderate disease, the regular use of emollients and either topical corticosteroids or calcineurin inhibitors are recommended $[13,14]$. These agents are in most situations able to bring relief to the patient. They may, however, not be sufficient in more recalcitrant cases in patients with moderate to severe disease.

\section{Systemic Therapies}

Despite poor evidence, systemic corticosteroids in combination with sedating antihistamines or the use of time-consuming phototherapy are sometimes used [14]. Systemic corticosteroids are in general not recommended treatments for $\mathrm{AD}$. Patients with severe disease refractory to conventional therapy may be treated with systemic non-steroidal treatment options with varying levels of evidence including cyclosporine A, methotrexate, azathioprine, and mycophenolate mofetil. All these options have a proven effect in the treatment of inflammatory skin disorders, including AD [15-19]. Nevertheless, these drugs are non-specific immunosuppressants, each with its own unique set of undesirable side effects.

Emerging Systemic Treatments in AD

\section{Immunopathology of $A D$}

The debate on the pathogenesis of $\mathrm{AD}$ concerning the inside-out versus the outside-in theory is not the subject of this paper; however, it is universally agreed upon that a compromised epidermal barrier function and a Th2/ Th22-dominated immune deviation are both central events in the development of the disease. The pathophysiology underlying the inflammatory response in $\mathrm{AD}$ is an exceedingly complex cytokine-mediated intercellular communication network. Cytokines most commonly bind to a specific cell-signalling receptor, initiating a cascade of events within the target cell. This consequently leads to differentiation and maturation of the targeted cell, regulation of specific gene transcripts, and subsequently an altered production of other cytokines and/or chemoattraction. Targeting key mediators of disease, either via narrow isolated effects or broader downstream actions, is a potential means to alleviate the disease. Targeted and personalized therapy based on endophenotypic profiling and a greater comprehension of the pathogenesis of $\mathrm{AD}$ is the next step for drug development in $\mathrm{AD}$ [10, 20-24].

\section{Selecting Studies for This Paper}

This review is comprised of papers on emerging systemic therapies in $\mathrm{AD}$ and of data on current and completed clinical trials concerning new systemic treatment options for AD identified at clinicaltrials.gov. We selected $\mathrm{AD}$-related therapies that have been reported from randomized, controlled trials in phase II, phase III, and phase IV with a first received date after January 1,2014. If an agent was represented with more than 1 trial in the clinicaltrials.gov database, it was represented in the review and tables with only 1 study (Table 1 ). We focused on the emerging drugs which are developed based on reasonable evidence of a potential effect in $\mathrm{AD}$. In doing so, more speculative therapeutic approaches and alternative means of disease modification were prioritized lower down, despite a possible capacity to benefit AD patients. Lastly, to increase readability we excluded therapies that could be categorized as either traditional Chinese medicine, herbal medicine, probiotics, histamine or leukotriene blockers, immuno-adsorption, or immunostimulants. All reviewed targets and therapies are listed in Table 1.

\section{Anti-Interleukin-4 and/or Anti-Interleukin-13}

The Th2 cytokines interleukin (IL)- 4 and IL-13 and their downstream effects are prominent in $\mathrm{AD}[10,25$, 26]. Th2-associated cytokines have pleiotropic effects on 
Table 1. Reviewed targets and therapies

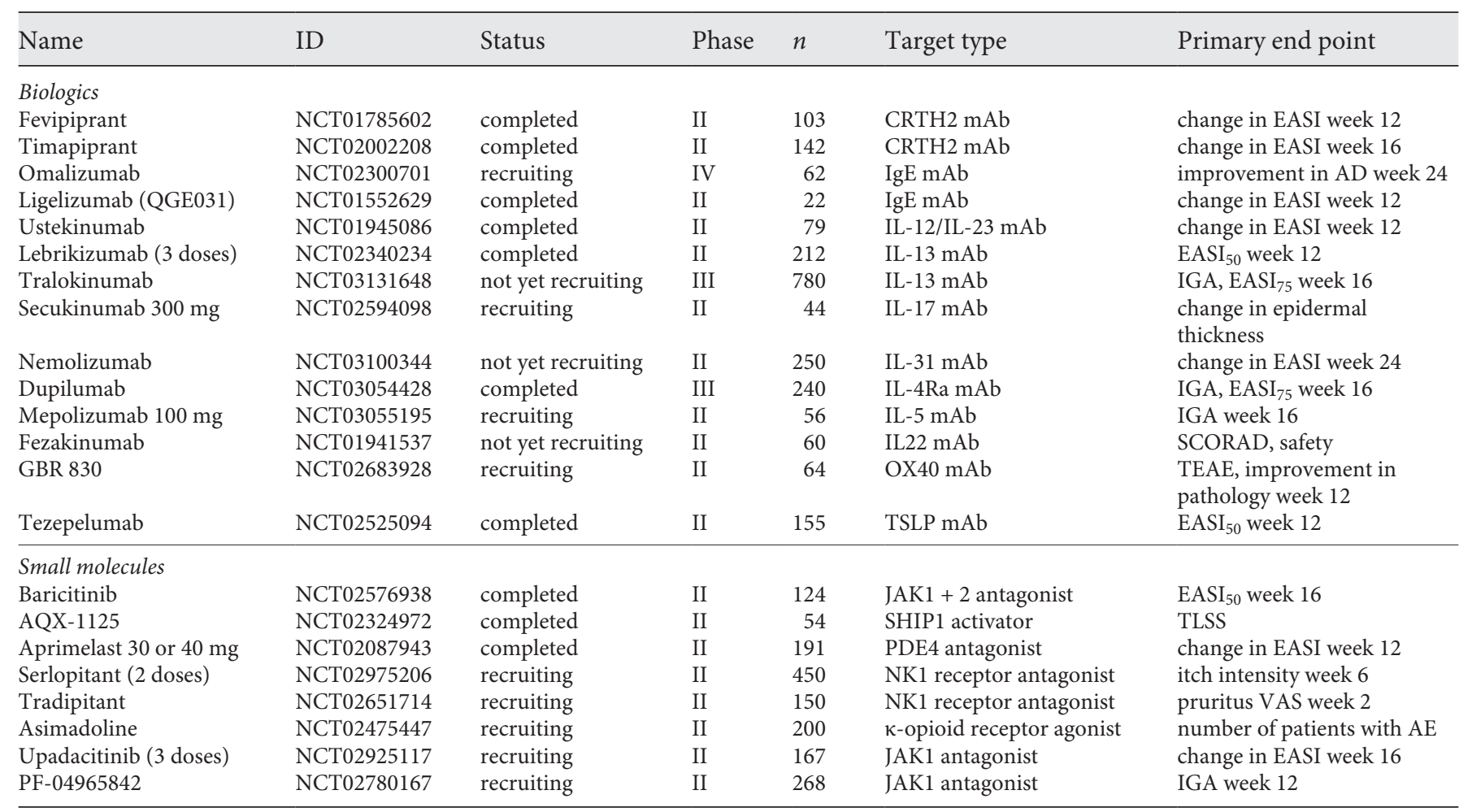

All studies are interventional randomized controlled trials. ID (unique NCT identifier) at www.clinicaltrial.gov, only primary end points are listed here. For secondary end points, please refer to www.clinicaltrial.gov. $n$, number of patients either recruited or to be recruited; CRTH2, chemoattractant receptor homologues molecule expressed on Th2 cells; mAb, monoclonal antibody; IgE, immunoglobulin E; IL, interleukin; TSLP, thymic stromal lymphopoietin; JAK, Janus kinase; SHIP1, SH2-containing inositol-5'-phosphatase 1; PDE, phosphodiesterase; NK, neurokinin; EASI, Eczema Area and Severity Index; IGA, Investigator's Global Assessment; EASI $50 / 75$, the percentage of patients achieving 50\%/75\% reduction in the EASI score; SCORAD, Scoring Atopic Dermatitis; TEAE, treatment-emerging adverse event; TLSS, target lesion symptom score; AE, adverse event; VAS, visual analogue scale.

the innate and adaptive immune system. In synergy with tumour necrosis factor $\alpha$, IL-4 and IL-13 induce thymic stromal lymphopoietin (TSLP) production in keratinocytes and augment the ongoing Th2 skewing of the immune system [27]. Further, IL-4 and IL-13 downregulate mRNA expression and protein synthesis of several structural barrier proteins including filaggrin, involucrin, and loricrin [28-31], thus inducing skin barrier dysfunction and aggravation of keratinocyte-mediated immune activation. Due to the Th2-driven inflammatory characteristics of AD, it seems sensible to inhibit Th2-related molecules, in order to reduce inflammation and break the detrimental feedback loop [32, 33].

\section{Dupilumab}

The humanized monoclonal antibody $(\mathrm{mAb})$ dupilumab binds to the $a$-subunit of the IL- 4 receptor, which is part of both the IL- 4 and IL-13 receptor complex. Thus, dupilumab modifies signalling of both the IL- 4 and IL-13 pathways. Dupilumab has been subjected to intensive investigation with an accumulated total of 15 completed or ongoing clinical trials. The safety and efficacy of dupilumab was primarily established in 3 placebo-controlled studies with a total of 2,119 adult participants with moderate to severe AD. Dupilumab showed significant clinical effects across 3 distinct severity assessment tools: Eczema Area and Severity Index (EASI), Investigator's Global Assessment (IGA), and SCORing Atopic Dermatitis (SCORAD) [34-36]. Moreover, dupilumab treatment significantly reduced pruritus. The dupilumabtreated patients displayed significant transcriptomic changes of lesional skin, most pronounced within genes related to dendritic cell activity and Th2-associated chemokines. No convincing effects were seen on pivotal structural barrier protein expression or on keratinocytederived cytokines [26]. An important observation was the positive effect of dupilumab independent of the patient's AD phenotype (low vs. high IgE or levels of serum thy- 
mus- and activation-regulated chemokine, CCL17), implying that dupilumab could be equally effective in intrinsic and extrinsic AD. Dupilumab treatment was in general well tolerated with few serious adverse events. Side effects such as non-infectious conjunctivitis and inflammation of the cornea were observed more commonly in the dupilumab group compared to placebo-treated subjects [34, 35]. In March 2017 the Food and Drug Administration approved dupilumab treatment for adults with moderate to severe $\mathrm{AD}$, as did the European Medicines Agency in 2017. Several ongoing studies involving both children and adolescents will show whether these subgroups of the $\mathrm{AD}$ population may experience equally positive effects, expanding the treatment indication for dupilumab further (NCT03054428).

\section{Tralokinumab}

Tralokinumab is an $\mathrm{mAb}$ that targets the cytokine IL13. The effects of tralokinumab were initially evaluated in asthma patients, where it did not significantly reduce disease severity measured by the Asthma Control Questionnaire ACQ6, though it did reduce the use of $\beta_{2}$-agonists. Subgroup analyses revealed an increased impact of tralokinumab in patients with a high baseline serum level of IL-13 indicating better efficacy in more Th2-polarized disease [37]. In a double-blind phase IIb study including 204 adults who suffered from moderate to severe AD, tralokinumab demonstrated efficacy in the primary and key secondary end points and had an adverse event profile comparable to placebo [38]. Treatment with tralokinumab for 12 weeks, 150 and $300 \mathrm{mg}$, significantly reduced the total EASI from baseline (adjusted mean difference of $-4.4, p=0.027$, and $-4.9, p=0.011$, respectively) compared with placebo. The number of patients achieving EASI $_{50}$ (reduction of EASI score by $50 \%$ ) at week 12 in the tralokinumab 300-mg group was significantly higher compared with placebo (73.4 vs. $51.9 \%, p=0.025)$. The patients were allowed to use topical corticosteroids in all treatment arms. The tralokinumab-treated group additionally revealed significant improvements in quality of life and pruritus (unpublished, presented at the annual meeting of the American Academy of Dermatology 2017). The most frequent adverse events in all groups (tralokinumab and placebo) were nasopharyngitis (17\%), upper respiratory tract infection (9\%), and headache (6\%) [38]. Several new phase III trials are planned (NCT02347176).

\section{Lebrikizumab}

Lebrikizumab is a humanized $\mathrm{mAb}$ that specifically targets IL-13 (NCT02340234). The drug was originally subjected to clinical evaluation in an asthmatic adult population [39]. Here it showed a significant improvement of disease severity indicated by increased forced expiratory volume in $1 \mathrm{~s}$ in the high-baseline periostin subgroup (biomarker correlating with Th2 immuno-activation). Furthermore, it also reduced the frequency of exacerbations of disease. Regarding adverse events, musculoskeletal side effects were more commonly reported in the lebrikizumab-treated group compared with placebo (13.2 vs. $5.4 \%)$. Other side effects were comparable in both groups. Since the turn of the year, 2 independent clinical trials further investigating the effects of lebrikizumab in asthma patients have been terminated due to poor efficacy. However, the data on the 2 phase II studies investigating the drug in adult patients with moderate to severe $\mathrm{AD}$ have yet to be revealed (NCT02340234).

\section{Anti-Interleukin-12/Anti-Interleukin-23}

IL-23 is thought to promote the expansion of both Th1 and Th17 T cells, and Th17 T cells have been reported to play a role in lesional skin of acute AD inflammation, while a Th1 component is primarily notable in the prolonged chronic phase of the disease [25, 40]. Consequently, by blocking IL-23 in AD, the Th17 and Th22 pathways are inhibited.

\section{Ustekinumab}

Ustekinumab is an $\mathrm{mAb}$ able to specifically bind the p40 protein subunit, present in both IL-23 and IL-12 (NCT01945086). Thus, binding its targets, ustekinumab is capable of disrupting the cytokine-driven propagation of Th17- and Th22-induced inflammation. Until recently only case series were reported on the effects of ustekinu$\mathrm{mab}$ in $\mathrm{AD}$ patients suffering from prolonged chronic moderate to severe $\mathrm{AD}$, with varying efficacy [41-43]. However, the first 2 randomized controlled trials comprising 79 and 33 patients in total have been completed, and the results show no significant decrease in severity scores. Thus, ustekinumab has a low potential as treatment for moderate to severe $\mathrm{AD}[44,45]$.

\section{Anti-Interleukin-17A}

The rationale behind targeted IL-17A therapy is the emerging evidence that Th17 T cells play a potentially greater part in the $\mathrm{AD}$-related immune activation, including attraction of neutrophils, than thought earlier $[10,46$, 
47]. Especially the subgroup of the AD population with low IgE and increased Th17 cell activation might be responsive to such therapy [25].

\section{Secukinumab}

Secukinumab is a $\mathrm{mAb}$ directed against IL-17A, registered for the treatment of severe psoriasis, psoriatic arthritis, and ankylosing spondylitis. A single phase II study involving 44 adults with $\mathrm{AD}$ (22 with intrinsic and 22 with extrinsic AD) is now recruiting (NCT02594098). As anti-IL-17A therapy in psoriasis increases the risk of neutropenia and skin and oral candida infections, it seems reasonable to be cautious, as $\mathrm{AD}$ patients are more prone to skin and mucosal infections than patients suffering from psoriasis.

\section{Anti-Interleukin-31/Anti-Interleukin-31 Receptor}

IL-31 is a member of the IL- 6 family and related to AD. It is mainly produced by Th2 cells and to a lesser extent dendritic cells, mast cells, and monocytes. Several studies have investigated IL-31 serum levels in AD patients and have shown inconsistent, but mainly elevated levels and correlation with disease severity [10, 48-51]. Emerging studies have indicated a critical role of IL-31 in the pathophysiology of itch [52-54]. This link is strengthened by (i) the augmentation of both the cytokine and its receptor complex on keratinocytes in involved and uninvolved skin of $\mathrm{AD}$ patients compared to healthy individuals and non-pruritic psoriatic patients [55], (ii) the stimulation with Th1 cell-derived interferon- $\gamma$ induces IL-31 receptor A upregulation in keratinocytes [56], (iii) IL-31 receptors are localized in dorsal root ganglia in humans [55], and (iv) increased scratching behaviour in transgenic mice overexpressing IL-31.

\section{Nemolizumab}

The $\mathrm{mAb}$ nemolizumab is directed against the IL-31 receptor $A$, which together with the oncostatin $\mathrm{M}$ receptor constitutes the functional IL-31 receptor. The first phase I study revealed a statistically significant $50 \%$ reduction in itch, assessed by the pruritus visual analogue scale, 4 weeks after initiation of treatment compared to the placebo group (20\% reduction) [57]. Moreover, nemolizumab decreased sleep disturbance and use of topical hydrocortisone. The study did not include any primary outcomes regarding disease severity. Side effects were nearly negligible encompassing increased creatine phosphokinase levels in the treatment group compared to placebo. A phase II study of nemolizumab in $264 \mathrm{AD}$ patients (moderate to severe) unable to adequately control disease activity by topical therapy shows significantly decreased pruritus [58]. However, despite marked reductions of both the EASI and SCORAD severity scores, these changes did not reach levels of statistical significance possibly due to sample size. A dose-ranging phase II study of the effects of nemolizumab (not yet recruiting) in moderate to severe $\mathrm{AD}$ subjects with severe pruritus with an estimated enrolment of 250 participants will supply additional evidence regarding the use of nemolizumab in AD (NCT03100344).

\section{BMS-981164 Monoclonal Antibody}

BMS-981164 is an mAb targeted at circulating IL-31, which completed an initial investigation in a phase I study 2 years back; however, results from this study have not been released, nor is any new trial announced.

\section{TSLP and Anti-OX40}

The relation between TSLP and the pathogenesis of $\mathrm{AD}$ is implied by its elevated expression in keratinocytes from $\mathrm{AD}$ patients and in skin samples subjected to barrier disruption by tape stripping [59-62]. Moreover, increased TSLP production in keratinocytes is facilitated by Staphylococcus aureus, a common skin-colonizing microorganism, in $\mathrm{AD}$ patients [63]. In $\mathrm{AD}$, serum levels of TSLP are significantly increased in both children and adults when compared to healthy controls $[10,64,65]$. TSLP has been shown to act as inducer of myeloid dendritic cells, Th2 responses, mast cells, and natural killer $T$ cells, thereby launching cytokine secretion and the development of $\mathrm{AD}$ [66]. When activating dendritic cells, TSLP facilitates a Th2-polarizing signal, priming naïve $\mathrm{T}$ cells to increased production of Th2-typical cytokines. In addition, the influence of TSLP on dendritic cells generates another highly Th2-polarizing signal, the OX40 ligand [67], which is pivotal in the generation of long-term Th2 memory response [68], optimal T-cell activation and inflammatory conditions like allergic asthma and AD [69, 70]. Taken together TSLP and OX40 are both pivotal cytokines in the activation and Th2 skewing of the immune system in $\mathrm{AD}$ [71].

\section{Tezepelumab (MEDI9929/AMG-157)}

Tezepelumab (formerly termed MEDI9929 and previously AMG-157) is an mAb directed against circulating TSLP. The phase I trial involving the drug was completed 
back in 2011, and the subsequent phase IIa, randomized, double-blind, placebo-controlled study to evaluate the efficacy and safety of MEDI9929 in 155 adult subjects with moderate to severe $\mathrm{AD}$ has recently been completed, though no data have been published yet (NCT02525094). However, in 2012 another anti-TSLP drug, MK-8226, was tested in a phase Ib study (NCT01732510), which was terminated in early testing, albeit no data posted. Thus, despite positive results in asthmatic subjects [72], and TSLP being a very meaningful target for $\mathrm{AD}$ therapy [73], antiTSLP treatment is still to prove valuable in the context of AD.

\section{GBR 830 Monoclonal Antibody}

The therapeutic mAb GBR 830 is an OX40 antagonist, exclusively binding and blocking the OX40-mediated signalling in $\mathrm{AD}$. It is the first OX40 antagonist globally to complete phase I studies, and it is now being evaluated in a larger phase II setting, still enrolling patients (NCT02683928). As OX40 has proven a potent costimulatory receptor on $\mathrm{T}$ cells, there is a potential promise that blocking this pathway and reverting the Th2 immune activation could mitigate a key pathogenic event and alleviate the disease.

\section{Targeting Janus Kinase/Signal Transducer and Activator of Transcription Pathways}

The Janus kinase/signal transducer and activator of transcription (JAK/STAT) signalling axis has been shown to play a critical role in the dysregulation of immune responses in $\mathrm{AD}$, involving amplification of Th2 cell response, instigation of eosinophils, and suppression of regulatory $\mathrm{T}$ cells [74]. In addition, the JAK/STAT pathway, when activated by IL-4, IL-13, and TSLP, plays an important role in the pathogenesis of $\mathrm{AD}$ by upregulating the expression of epidermally derived chemokines and a cascade of pro-inflammatory cytokines as well as downregulating structural epidermal proteins, e.g. filaggrin, involucrin, or loricrin, ultimately diminishing the skin barrier function [29, 30, 75-77]. Additionally, downstream signalling in this pathway has been shown to prevent the induction of genes encoding innate immune response proteins, including $\beta$-defensins and cathelicidin [78], thus raising the vulnerability of patients to both viral and bacterial skin infections. Inhibitors of the JAK/STAT signalling axis are categorized as small molecules blocking intracellular targets in comparison to anticytokine/antireceptor agents. The relevance in tar-

Emerging Systemic Treatments in AD geting this family of kinases is that they constitute the main signalling pathway for several cytokines, thus providing an opportunity to prevent the downstream signalling of numerous AD-typical Th2 cytokines. Several pharmaceutical agents targeting TYK2, JAK1, JAK2, and JAK3 are being evaluated for the treatment of moderate to severe $\mathrm{AD}$.

\section{Baricitinib}

Baricitinib is a small molecule inhibiting both JAK1 and JAK2. The first phase II study to investigate safety and efficacy of the drug has recently been completed (NCT02576938). A total of 124 adults with moderate to severe $\mathrm{AD}$ were enrolled, but no data from the study have been released yet. The drug has been thoroughly tested in rheumatoid arthritis (RA), psoriasis, alopecia areata, and other inflammatory or auto-immune conditions, with promising results and only few side effects primarily confined to a slightly increased rate of infection, risk of low neutrophils and reduced haemoglobin levels. Baricitinib is, in contrast to the mAbs, an oral treatment taken once daily, thus reducing costs and inconvenience for the patient in relation to administration.

\section{Tofacitinib}

Tofacitinib is another small molecule. It inhibits JAK1 and JAK 3 and in theory interferes to a larger extent with lymphocyte activation and Th2 skewing than the inhibitors also targeting JAK2 which are more involved in Th1 signalling [79]. It has been studied in a minor case series involving 6 patients revealing a significant reduction in SCORAD [80]. The oral formulation of the drug is not subject to any clinical trials involving $\mathrm{AD}$; however, it is already approved for severe RA, and is in phase III trials for psoriasis. Side effects comprise increased rates of diarrhoea, infections, low neutrophils and lymphocytes, and increased levels of creatinine and lipids, and more concerning a possible increased risk of lymphoma [81, 82].

\section{Upadacitinib}

Upadacitinib is a small molecule targeting only JAK1. It is investigated in a phase IIb placebo-controlled multicentre study to evaluate the safety and efficacy in adult participants with moderate to severe AD (NCT02925117). There are many other studies of upadacitinib with 15 ongoing and 3 completed involving a range of diagnoses including both RA and Crohn's disease. Positive results were seen, and the safety profile was reasonable with increased rates of infections as a main finding $[83,84]$. 


\section{PF-04965842 Molecule}

PF-04965842 is a small molecule targeting solely JAK1. It completed phase I trials in both Europe and Asia in 2014 , and its safety and efficacy are now evaluated in a phase II trial of adults with moderate to severe $\mathrm{AD}$ (NCT02780167). A discontinued phase II study in psoriasis patients (NCT02201524 - not terminated for reasons of safety and/or efficacy) revealed some effects on PASI and no serious adverse events. Rates of adverse events were markedly increased in the high-dose group compared to placebo, but it was primarily reports of nausea, headache, and hypertension.

\section{Inhibiting the Enzyme Phosphodiesterase-4}

The potential therapeutic use of phosphodiesterase- 4 (PDE4) inhibitors in a variety of inflammatory diseases, including $\mathrm{AD}$, is based on the recognized intracellular role of PDE4 in keratinocytes $[85,86]$. PDE4 is an enzyme which is increased in $\mathrm{AD}$ and in part is responsible for the hydrolyzation of cyclic adenosine monophosphate (cAMP) [87]. This consequently diminishes levels of cAMP, which lead to increased transcription of numerous cytokines, including pro-inflammatory ones, and accelerates a number of other intracellular functions involved in acute and chronic inflammation [87]. Currently, there are several trials investigating various topically and systemically administered PDE4 inhibitors that suppress the release of pivotal pro-inflammatory cytokines which elicit AD flares [88].

\section{Apremilast}

Apremilast is an oral PDE4 inhibitor evaluated in 2 smaller open-label phase II studies and 1 larger recently completed trial for patients with moderate to severe AD (NCT02087943). The minor studies revealed modest reduction of EASI and the IGA score, with the key side effects not unexpectedly being nausea, vomiting, and headache $[89,90]$. Results from the newest study have just been listed in clinicaltrials.gov (NCT02087943) but are not published yet. Compared to placebo treatment, apremilast 30 or $40 \mathrm{mg}$ daily demonstrates mean EASI reductions of -15.01 and -20.60 points, respectively, at 12 weeks, with only the latter being a statistically significant drop. The percentage of participants who achieved a score of 0 (clear) or 1 (almost clear) and at least a 2-point reduction from baseline in a Static Physician's Global Assessment of Acute Signs at week 12 did not reach statistically significant levels in either treatment group when compared to placebo. Neither did the average weekly pruritus Numerical Rating Scale score at week 4 decrease significantly. Few serious adverse events were reported in both the 30- and 40-mg treatment groups and comprised sporadic cases of cellulitis, pneumonia, glomerulonephritis and squamous cell carcinoma. The rate of less serious side effects was markedly higher in both treatment groups compared to placebo and included predominantly typical PDE4-related gastrointestinal disorders like nausea, vomiting, abdominal discomfort, and diarrhoea; moreover, nasopharyngitis was more commonly seen in the treatment groups.

\section{Chemoattractant Receptor Homologues Molecule Expressed on Th2 Cells Antagonist}

Chemoattractant receptor homologues molecule expressed on Th2 cells (CRTH2 or $\mathrm{DP}_{2}$ ) is a receptor for the ligand prostaglandin $\mathrm{D}_{2}$, which is a product from cyclooxygenase activity. When exposed to an allergen challenge, the production of prostaglandin $\mathrm{D}_{2}$ increases, and when binding to CRTH2 it facilitates the activation and a positive feedback loop in chemotaxis of Th2 cells, eosinophils, and to lesser extent basophils [91]. CRTH2 signalling is thought to be involved in the activation of allergological pathways and Th2 immune activation [92]; thus, the development of small molecules targeting the CRTH2 could be beneficial to $\mathrm{AD}$ patients as a means of correcting a skewed Th2 response and reducing eosinophil activity.

\section{Fevipiprant}

Two CRTH2 antagonists have recently completed phase II trials, fevipiprant (NCT01785602) and timapiprant (NCT02002208). Data on both studies are accessible on clinicaltrials.gov but are somewhat scarce and supply no statistical analyses estimating levels of significance. The fevipiprant study of $103 \mathrm{AD}$ patients with three fourths receiving the active drug revealed a mean EASI reduction from baseline of -8.65 points in the fevipiprant group and -6.95 points in the placebo group. Despite negligible standard errors of the mean (both 0.01), it is doubtful whether this holds any clinical significance.

\section{Timapiprant}

The timapiprant study included 142 patients, with 139 finishing the study, randomized 1:1 to either $50 \mathrm{mg}$ daily of timapiprant or placebo. The effect on the primary end point of change from baseline EASI was a reduction of -3.8 points (standard error 1.72) in the treatment group 
and -6.1 points (standard error 1.71) in the placebo group, thus evidently there was no meaningful treatment response. Taken together the $\mathrm{CRTH} 2$ antagonist does not look promising in the adult subset of AD patients with moderate to severe disease.

\section{SH2-Containing Inositol-5'-Phosphatase 1 Activator}

SH2-containing inositol-5' ${ }^{\prime}$-phosphatase 1 (SHIP1) is an endogenous inhibitor of the phosphoinositide-3-kinase pathway that is involved in the activation and chemotaxis of various immune cells. SHIP1 is capable of downregulating the signalling processes in cells of the haematopoietic lineage predominantly, including many inflammatory cells [93]. SHIP1 mediates its downregulatory function after repositioning from a cytoplasmic localization to the plasma membrane where it converts its substrate, thereby terminating phosphatidylinositide3-kinase-mediated signalling [94]. Consequently, SHIP1 interferes with immune cells to diminish their activation and migration, thereby reducing inflammation. Drugs that activate SHIP1 can therefore potentially reduce the activity and function of AD-involved immune cells and have an anti-inflammatory effect.

\section{AQX-1125 Molecule}

AQX-1125 is a small molecule administered by daily oral dosing, evaluated in a study to assess the effect of 12 weeks of treatment compared to placebo on change from baseline in Target Lesion Symptom Score (TLSS) in subjects with mild to moderate AD (NCT02324972). The results from the completed study are accessible in a modified form as a press release from the manufacturing company [95]. In conclusion, the AQX-1125 phase II trial failed to demonstrate efficacy in 54 patients with mild to moderate $\mathrm{AD}$ evaluated by the primary end point TLSS at week 12 compared to baseline. It was stated that the trial demonstrated AQX-1125 to be well tolerated and adverse events were consistent with prior clinical trials [95]. No serious adverse events were recorded during the trial.

\section{Anti-IL-22 Antibody}

Recently, a new subset of Th cells producing IL-22 in the absence of IL-17 was identified and characterized in AD skin inflammation [96]. These skin-homing Th22 cells express the CC chemokine receptors CCR4 and CCR10, and are increased in acute and chronic lesion skin of $\mathrm{AD}$ patients correlating with disease severity $[40,75,97$, 98]. IL-22 mediates its cellular effects via a heterodimeric receptor complex composed of IL-22 receptor subunit 1 (IL-22R1) and IL-10R2, the IL-22R1 being primarily present on keratinocytes and other skin-resident cells [98]. The effects of IL-22 signalling in keratinocytes have been described to hamper filaggrin expression and processing and thereby impairing the epithelial barrier [99]. Moreover, IL-22 is able to impede the keratinocyte terminal differentiation and to prompt epidermal hyperplasia as seen in chronic $\mathrm{AD}$ [96]. In conclusion, the involvement of this novel Th-cell subset and the production of IL-22 could be targeted in AD and help improve disease [100].

\section{Fezakinumab (ILV-094)}

Fezakinumab is an $\mathrm{mAb}$ that binds and blocks the actions of IL-22. It is being trialled in a phase II study of estimated 60 adult $\mathrm{AD}$ patients with chronic moderate to severe disease (NCT01941537). As the bulk of data on IL22 -mediated inflammation and possible effects of antiIL-22 therapy have been obtained from animal models, which may not be applicable to humans, this study might be the first to shed light on the possible implications of Th22/IL-22 signalling in AD. Fezakinumab was previously studied in a phase I study in psoriasis and a phase II study in RA, but the results were never communicated, and these indications have been abandoned.

\section{Anti-IL-5 Antibody}

Elevated numbers of blood and tissue eosinophils are often present in $\mathrm{AD}[101,102]$, and evidence suggests that eosinophils play a perhaps restricted, but still noticeable role in the disease pathogenesis. Eosinophils are important producers of IL-5, and moreover the regulation of eosinophil maturation, recruitment, and survival is partially under the control of IL-5 [103]. Given the role of eosinophils in allergy and atopic disease, IL-5 is a potential molecular target in the treatment of these diseases [104].

\section{Mepolizumab}

Mepolizumab is a humanized mAb that acts on IL-5. Anti-IL-5 therapy has been subject to intensive studies in both allergic asthma and eosinophil oesophagitis [105], and to a much lesser degree in $\mathrm{AD}$. A randomized placebo-controlled parallel-group study involving adult $\mathrm{AD}$ patients with refractory disease, where 18 received active treatment, has been performed. The conclusion from the 
authors was that 2 single doses of mepolizumab, despite reduction in circulating eosinophil count, did not produce a clinically relevant improvement in patients with $\mathrm{AD}$ assessed by validated measures of dermatitis and pruritus [106].

Now, a decade later, mepolizumab is in a phase II study investigating the efficacy and safety of mepolizumab subcutaneously administered every 4 weeks compared with placebo in adults with moderate to severe $\mathrm{AD}$ (NCT03055195). It is noteworthy that there is a discrepancy in the treatment response of anti-IL-5 therapy in relation to the drug delivery platform (subcutaneous vs. intravenous), a concern previously addressed [107]. The safety profile for mepolizumab has been proven to be decent [105].

\section{Kappa-Opioid Receptor Agonists}

Pruritus is a symptom occurring due to a mix of dermatological, neurological, and systemic circumstances. The highly complex pathophysiological mechanisms enabling both acute and chronic itch are thus not yet fully understood. In the last decade research has improved the conception of these mechanisms, facilitating the development of new drugs targeting pruritus. Explicitly, new treatments for inflammatory dermatoses are being tested in several ongoing randomized clinical trials. In the context of $\mathrm{AD}$, neurokinin 1 receptor $(\mathrm{NK} 1)$ receptor antagonists, IL-31 and IL-31 receptor A antibodies (described earlier), as well as $\kappa$-opioid receptor (KOR) agonists are pharmaceutical agents in the pipeline that besides a potential to alleviate itch might also dampen the inflammatory response.

Opioid receptors are identified regulators of the sensation of itch in the central nervous system. In the brain, $\mu$-opioid receptors can augment itch, while KORs may, by contrast, reduce or even alleviate itch [108]. It is not known whether the peripheral opioid receptor system, expressed by skin components, e.g. keratinocytes and nerve terminals, participates in initiating and transmitting itch signalling. Interestingly, KOR is present in the skin, and when targeted it may show effects similar to those in the central nervous system [109].

\section{Asimadoline}

Asimadoline is a small molecule which acts as a peripherally highly selective KOR agonist. As asimadoline is merely capable of crossing the blood-brain barrier, it lacks the undesired psychotomimetic effects of other cen- trally acting KOR agonists and therefore holds greater potential for medical use. The drug is evaluated in a phase II study to assess the safety, pharmacokinetics, and preliminary efficacy in adults with $\mathrm{AD}$-associated pruritus (NCT02475447). The study is currently enrolling patients (estimated enrolment: 200), and it will be its first aim to clarify whether an activation of peripheral KORs is a feasible strategy in alleviating itch.

\section{NK1 Antagonists}

NK1 antagonists are a new class of drugs that possesses unique properties as anti-emetics and anxiolytics, thus they have seen extensive use in the treatment of chemotherapy-associated nausea and vomiting. Signalling via the NK1 receptor is mediated by several different neuropeptides, the most prominent being substance P (SP), which act as a neurotransmitter and as a neuromodulator [110]. SP and the NK1 receptor are both widely distributed in the brain and the skin where the SP is a key first responder to most harmful stimuli. Despite SP being best known as mediator of anxiety, pain, and vomiting, there is evidence that, in inflammatory dermatoses with elements of chronicity, including $\mathrm{AD}$, there are high levels of SP associated with increased pruritus [111, 112]. Thus, an NK1 antagonist might hold the potential to counter the SP-mediated itching in AD patients $[113,114]$.

\section{Tradipitant (VLY-686 or LY686017)}

The NK1 antagonist tradipitant is an experimental drug that blocks SP, currently trialled in a phase II study (NCT02651714). It was primarily investigated in a proofof-concept study in adults with treatment-resistant pruritus associated with $\mathrm{AD}$. The 1:1 randomization of 68 atopic adults receiving either $100 \mathrm{mg}$ of tradipitant orally once daily (in the evening) or placebo has revealed somewhat positive results, however, only published in the form of a press release and not a scientific paper [115]. Despite a significant improvement from baseline by tradipitant (40.5 $\mathrm{mm}$ improvement from baseline, $p<0.0001$ ) as measured on a $100-\mathrm{mm}$ unit visual analogue scale for itch, a high placebo effect ( $36.5 \mathrm{~mm}$ improvement from baseline, $p<0.0001)$ on the change from baseline led to no statistical difference from placebo [115]. However, in a subgroup analysis half of the participants who were assessed in the morning (compared to the other half in the afternoon) showed that this group had a significant change in itch visual analogue scale score compared to placebo [115]. End points corresponding to the underly- 
ing disease severity, e.g. SCORAD, EASI, and Dermatological Quality of Life Index, showed no significant difference from placebo. In conclusion, there are no dramatic effects seen from tradipitant treatment of AD. Twice daily administrations might prove meaningful.

\section{Serlopitant (VPD-737)}

Serlopitant is another small molecule with NK1 antagonistic properties. Serlopitant is a once-daily oral NK1 antagonist under development exclusively for the treatment of severe chronic pruritus. In a recent not yet published multicentre, placebo-controlled phase II trial involving 257 patients with severe refractory chronic pruritus of various aetiologies, 6 weeks of serlopitant at 1 or $5 \mathrm{mg} /$ day were distinctly more effective than placebo in reducing itch intensity [116]. Those data since spurred the ATOMIK study, with the purpose of investigating the efficacy, safety, and tolerability of serlopitant (high or low dose) compared to placebo for treating pruritus in adult AD patients (NCT02975206 - estimated enrolment 450 patients). The ATOMIK study will be pivotal in generating ample evidence in order to confirm or dismiss the use of an NK1 antagonist in AD.

\section{Anti-IgE Therapy}

The implication and importance of elevated IgE levels in $\mathrm{AD}$ is the topic of an unrelenting discussion. IgE acts as a differentiator between extrinsic (high IgE, atopic comorbidities, elevated eosinophils and family history of atopy) and intrinsic $\mathrm{AD}$ (none of the above). However, it is debatable whether this stratification of the total $\mathrm{AD}$ population is in any way meaningful. Newer studies show that there is little to no difference between the 2 groups regarding the systemic Th2 skewing and immunomodulation [25], nor do qualified endophenotypic profiling and subtyping show a role of $\operatorname{IgE}[10,20]$. Thus, it is reasonable to speculate that IgE is merely a signature molecule reflecting the skewed immune response with high IL-4 as well as atopic comorbidities and not a pathophysiological key player. The reason for targeting IgE is somewhat clouded and might be a means to alleviate distress from atopy in general rather than $\mathrm{AD}$ inflammation specifically.

\section{Omalizumab}

Omalizumab is a recombinant DNA-derived humanized IgG1 $\mathrm{k} \mathrm{mAb}$ that specifically binds to circulating IgE and to membrane-bound IgE on the surface of B lympho- cytes [117]. Omalizumab inhibits the binding of IgE to the high-affinity IgE receptor (FceRI) on mast cells and basophils, thus inhibiting their activation and subsequently their discharge of chemical mediators including histamine [118]. Interestingly, omalizumab treatment also depletes free IgE which gradually downregulates the FceRI on target cells and consequently functions as a mast cell-stabilizing drug [118]. This has been the reason for the widespread use in chronic idiopathic urticaria and steroid-dependent allergic asthma. However, a communal interpretation of 5 case series and a single randomized placebo-controlled study concludes no considerable effects from omalizumab on AD disease activity [119-123]. Yet, omalizumab treatment is trialled again in a randomized placebo-controlled phase II study to evaluate the efficacy of anti-IgE therapy in children with severe recalcitrant AD (NCT02300701). One inclusion criterion is a total IgE level above $300 \mathrm{kU} / \mathrm{L}$. Thus, it is targeting the extrinsic subsection of severe paediatric $\mathrm{AD}$, and this is possibly the last feasible study that will ultimately either identify a subgroup of patients with beneficial effects from anti-IgE treatment or finally dismiss the use of this class of drugs in $\mathrm{AD}$.

\section{Ligelizumab (QGE031)}

Ligelizumab as an $\mathrm{mAb}$ targets IgE with some pharmacological differences to omalizumab. Ligelizumab binds with high affinity to the Ce3 domain of IgE, and in comparison to omalizumab, ligelizumab demonstrates a 6- to 9-fold higher suppression of allergen-induced skin prick test response. Moreover, ligelizumab is able to provide a greater and more prolonged attenuation of both circulating IgE levels and IgE on the surface of free basophils as compared to omalizumab [124]. Ligelizumab is studied in a phase II trial assessing safety and efficacy in the treatment of moderate to severe adult AD patients (NCT01552629). The study has 3 treatment arms with ligelizumab, cyclosporine $\mathrm{A}$, or placebo (randomization unknown) and has been complete with a total of 22 patients enrolled. Data have not been communicated yet, but it is doubtful that a study of this size will be able to substantiate the use of this more potent anti-IgE molecule in the context of $\mathrm{AD}$.

\section{Conclusion}

Novel insights into the aetiopathogenesis of $\mathrm{AD}$ met by the medical industry have crowded the pipeline with exciting new therapies and treatment modalities to im- 
prove the lives of $\mathrm{AD}$ patients. The bulk of upcoming therapies is directed at the type 2 immunomodulation, and several targets down the Th2 axis seem highly promising due to direct and indirect downstream modulation of the AD-related signs and symptoms. With the lack of sustainable and cost-efficient treatment options for severe, recalcitrant, and chronic $\mathrm{AD}$, the effects obtained by key cytokine antagonisms have brightened the future for the treatment of this disease.

\section{Key Message}

The amount of novel systemic drugs in the development for treating atopic dermatitis is ever increasing and may hold a promise of better treatment for patients with severe, recalcitrant and chronic disease. We present emerging therapies in a systematic fashion by summarizing the major background information on each therapeutic target, directly followed by an appraisal of the ex- isting data and studies involving the drugs in this category. The aim of this review is to make a vast field of research easily accessible to anyone interested in the advancement of $\mathrm{AD}$-related drugs.

\section{Disclosure Statement}

M.D. is an investigator, speaker, and/or advisor for AbbVie A/S, Pierre Fabre Dermo-Cosmétique, Meda Pharma, Leo Pharma, Sanofi-Genzyme, and Regeneron. C.V. is an investigator for AbbVie A/S and Pierre Fabre Dermo-Cosmétique. He has served on advisory boards for Astellas Pharma and has been a speaker for Leo Pharma, Astellas, MSD, AbbVie, Novartis, and Pfizer. U.N. declares no relevant conflicts of interest.

\section{Author Contributions}

All authors have participated sufficiently in the work to take public responsibility for its contents as stated at http://www.publicationethics.org.uk.

\section{References}

1 Weidinger S, Novak N: Atopic dermatitis. Lancet 2016;387:1109-1122.

2 Flohr C, Mann J: New insights into the epidemiology of childhood atopic dermatitis. Allergy 2014;69:3-16.

3 Silverberg JI, Simpson EL: Associations of childhood eczema severity: a US populationbased study. Dermatitis 2014;25:107-114.

4 Silverberg JI, Hanifin J, Simpson EL: Climatic factors are associated with childhood eczema prevalence in the United States. J Invest Dermatol 2013;133:1752-1759.

5 Engebretsen KA, Bager P, Wohlfahrt J, Skov L, Zachariae C, Nybo Andersen AM, et al: Prevalence of atopic dermatitis in infants by domestic water hardness and season of birth: cohort study. J Allergy Clin Immunol 2017; 139:1568-1574.

6 Irvine AD, McLean WH, Leung DY: Filaggrin mutations associated with skin and allergic diseases. N Engl J Med 2011;365:1315-1327.

7 Nygaard U, Riis JL, Deleuran M, Vestergaard C: Attention-deficit/hyperactivity disorder in atopic dermatitis. An appraisal of the current literature. Pediatr Allergy Immunol Pulmonol 2016;29:181-188.

8 Andersen YMF, Egeberg A, Skov L, Thyssen JP: Comorbidities of atopic dermatitis: beyond rhinitis and asthma. Curr Dermatol Rep 2017;6:35-41.

9 Simpson EL, Chalmers JR, Hanifin JM, Thomas KS, Cork MJ, McLean WH, et al: Emollient enhancement of the skin barrier from birth offers effective atopic dermatitis prevention. J Allergy Clin Immunol 2014;134: 818-823.
10 Nygaard U, Hvid M, Johansen C, Buchner M, Folster-Holst R, Deleuran M, et al: TSLP, IL31 , IL-33 and sST2 are new biomarkers in endophenotypic profiling of adult and childhood atopic dermatitis. J Eur Acad Dermatol Venereol 2016;30:1930-1938.

11 Riis JL, Vestergaard C, Deleuran MS, Olsen M: Childhood atopic dermatitis and risk of attention deficit/hyperactivity disorder: a cohort study. J Allergy Clin Immunol 2016;138: 608-610.

12 Nygaard U, Vestergaard C, Deleuran M: Systemic treatment of severe atopic dermatitis in children and adults. Curr Treat Options Allergy 2014;1:384-396.

13 Proudfoot LE, Powell AM, Ayis S, Barbarot S, Baselga Torres E, Deleuran M, et al: The European Treatment of Severe Atopic Eczema in Children Taskforce (TREAT) survey. Br J Dermatol 2013;169:901-909.

14 Sidbury R, Davis DM, Cohen DE, Cordoro KM, Berger TG, Bergman JN, et al: Guidelines of care for the management of atopic dermatitis. 3. Management and treatment with phototherapy and systemic agents. J Am Acad Dermatol 2014;71:327-349.

15 El-Khalawany MA, Hassan H, Shaaban D, Ghonaim N, Eassa B: Methotrexate versus cyclosporine in the treatment of severe atopic dermatitis in children: a multicenter experience from Egypt. Eur J Pediatr 2013;172:351356.

16 Silverberg JI: Atopic dermatitis: an evidencebased treatment update. Am J Clin Dermatol 2014; 15:149-164.
17 Schram ME, Roekevisch E, Leeflang MM, Bos JD, Schmitt J, Spuls PI: A randomized trial of methotrexate versus azathioprine for severe atopic eczema. J Allergy Clin Immunol 2011; 128:353-359.

18 Schram ME, Borgonjen RJ, Bik CM, van der Schroeff JG, van Everdingen JJ, Spuls PI: Offlabel use of azathioprine in dermatology: a systematic review. Arch Dermatol 2011;147: 474-488.

19 Haeck IM, Knol MJ, Ten Berge O, van Velsen SG, de Bruin-Weller MS, Bruijnzeel-Koomen CA: Enteric-coated mycophenolate sodium versus cyclosporin $\mathrm{A}$ as long-term treatment in adult patients with severe atopic dermatitis: a randomized controlled trial. J Am Acad Dermatol 2011;64:1074-1084.

20 Thijs J, Strickland I, Bruijnzeel-Koomen C, Nierkens S, Giovannone B, Csomor E, et al: Moving towards endotypes in atopic dermatitis: identification of patient clusters based on serum biomarker analysis. J Allergy Clin Immunol 2017;140:730-737.

21 Guttman-Yassky E, Krueger JG, Lebwohl MG: Systemic immune mechanisms in atopic dermatitis and psoriasis with implications for treatment. Exp Dermatol 2017, Epub ahead of print.

22 Thijs JL, de Bruin-Weller MS, Hijnen D: Current and future biomarkers in atopic dermatitis. Immunol Allergy Clin North Am 2017; 37:51-61.

23 Ardern-Jones MR, Bieber T: Biomarkers in atopic dermatitis: it is time to stratify. $\mathrm{Br} \mathrm{J}$ Dermatol 2014;171:207-208. 
24 Bieber T: Atopic dermatitis 2.0: from the clinical phenotype to the molecular taxonomy and stratified medicine. Allergy 2012;67: 1475-1482.

25 Suarez-Farinas M, Dhingra N, Gittler J, Shemer A, Cardinale I, de Guzman Strong C, et al: Intrinsic atopic dermatitis shows similar TH2 and higher TH17 immune activation compared with extrinsic atopic dermatitis. J Allergy Clin Immunol 2013;132:361-370.

26 Hamilton JD, Suarez-Farinas M, Dhingra N, Cardinale I, Li X, Kostic A, et al: Dupilumab improves the molecular signature in skin of patients with moderate-to-severe atopic dermatitis. J Allergy Clin Immunol 2014;134: 1293-1300.

27 Bogiatzi SI, Fernandez I, Bichet JC, MarloieProvost MA, Volpe E, Sastre X, et al: Cutting edge: proinflammatory and Th2 cytokines synergize to induce thymic stromal lymphopoietin production by human skin keratinocytes. J Immunol 2007;178:3373-3377.

28 Kim BE, Leung DY, Boguniewicz M, Howell $\mathrm{MD}$ : Loricrin and involucrin expression is down-regulated by Th2 cytokines through STAT-6. Clin Immunol 2008;126:332-337.

29 Howell MD, Kim BE, Gao P, Grant AV, Boguniewicz M, Debenedetto A, et al: Cytokine modulation of atopic dermatitis filaggrin skin expression. J Allergy Clin Immunol 2007;120: 150-155.

30 Nygaard U, van den Bogaard EH, Niehues $\mathrm{H}$, Hvid M, Deleuran M, Johansen C, et al: The "alarmins" HMBG1 and IL-33 downregulate structural skin barrier proteins and impair epidermal growth. Acta Derm Venereol 2017; 97:305-312.

31 Van den Bogaard EH, Bergboer JG, VonkBergers M, van Vlijmen-Willems IM, Hato SV, van der Valk PG, et al: Coal tar induces AHR-dependent skin barrier repair in atopic dermatitis. J Clin Invest 2013;123:917-927.

32 Andrews AL, Holloway JW, Holgate ST, Davies DE: IL-4 receptor alpha is an important modulator of IL-4 and IL-13 receptor binding: implications for the development of therapeutic targets. J Immunol 2006;176:74567461.

33 Werfel T, Biedermann T: Current novel approaches in systemic therapy of atopic dermatitis: specific inhibition of cutaneous Th2 polarized inflammation and itch. Curr Opin $\mathrm{Al}-$ lergy Clin Immunol 2015;15:446-452.

34 Thaci D, Simpson EL, Beck LA, Bieber T, Blauvelt A, Papp K, et al: Efficacy and safety of dupilumab in adults with moderate-tosevere atopic dermatitis inadequately controlled by topical treatments: a randomised, placebo-controlled, dose-ranging phase $2 \mathrm{~b}$ trial. Lancet 2016;387:40-52.

35 Beck LA, Thaci D, Hamilton JD, Graham NM, Bieber T, Rocklin R, et al: Dupilumab treatment in adults with moderate-to-severe atopic dermatitis. N Engl J Med 2014;371: 130-139.
36 Simpson EL, Bieber T, Guttman-Yassky E, Beck LA, Blauvelt A, Cork MJ, et al: Two phase 3 trials of dupilumab versus placebo in atopic dermatitis. N Engl J Med 2016;375: 2335-2348.

37 Brightling CE, Chanez P, Leigh R, O'Byrne PM, Korn S, She D, et al: Efficacy and safety of tralokinumab in patients with severe uncontrolled asthma: a randomised, doubleblind, placebo-controlled, phase $2 \mathrm{~b}$ trial. Lancet Respir Med 2015;3:692-701.

38 Wollenberg A, Howell MD, Guttman-Yassky E, Silverberg JI, Birrel C, Kell C: A phase 2b dose-ranging efficacy and safety study of tralokinumab in adult patients with moderate to severe atopic dermatitis (AD) (poster No 4496). 75th Annual Meeting of the American Academy of Dermatology, Orlando, 2017.

39 Corren J, Lemanske RF, Hanania NA, Korenblat PE, Parsey MV, Arron JR, et al: Lebrikizumab treatment in adults with asthma. N Engl J Med 2011;365:1088-1098.

40 Gittler JK, Shemer A, Suarez-Farinas M, Fuentes-Duculan J, Gulewicz KJ, Wang CQ, et al: Progressive activation of $\mathrm{T}(\mathrm{H}) 2 / \mathrm{T}(\mathrm{H}) 22$ cytokines and selective epidermal proteins characterizes acute and chronic atopic dermatitis. J Allergy Clin Immunol 2012;130: 1344-1354.

41 Wlodek C, Hewitt H, Kennedy CT: Use of ustekinumab for severe refractory atopic dermatitis in a young teenager. Clin Exp Dermatol 2016;41:625-627.

42 Puya R, Alvarez-Lopez M, Velez A, Casas Asuncion E, Moreno JC: Treatment of severe refractory adult atopic dermatitis with ustekinumab. Int J Dermatol 2012;51:115116.

43 Samorano LP, Hanifin JM, Simpson EL, Leshem YA: Inadequate response to ustekinumab in atopic dermatitis - a report of two patients. J Eur Acad Dermatol Venereol 2016; 30:522-523.

44 Khattri S, Brunner PM, Garcet S, Finney R, Cohen SR, Oliva M, et al: Efficacy and safety of ustekinumab treatment in adults with moderate-to-severe atopic dermatitis. Exp Dermatol 2017;26:28-35.

45 Saeki H, Kabashima K, Tokura Y, Murata Y, Shiraishi A, Tamamura R, et al: Efficacy and safety of ustekinumab in Japanese patients with severe atopic dermatitis: a randomised, double-blind, placebo-controlled, phase 2 study. Br J Dermatol 2017;177:419-427.

46 Nograles KE, Zaba LC, Guttman-Yassky E, Fuentes-Duculan J, Suarez-Farinas M, Cardinale I, et al: Th17 cytokines interleukin (IL)17 and IL-22 modulate distinct inflammatory and keratinocyte-response pathways. $\mathrm{Br} \mathrm{J}$ Dermatol 2008;159:1092-1102.

47 Xu D, Jiang HR, Kewin P, Li Y, Mu R, Fraser $A R$, et al: IL-33 exacerbates antigen-induced arthritis by activating mast cells. Proc Natl Acad Sci USA 2008;105:10913-10918.
48 Raap U, Weissmantel S, Gehring M, Eisenberg AM, Kapp A, Folster-Holst R: IL-31 significantly correlates with disease activity and Th2 cytokine levels in children with atopic dermatitis. Pediatr Allergy Immunol 2012;23: 285-288.

49 Raap U, Wichmann K, Bruder M, Stander S, Wedi B, Kapp A, et al: Correlation of IL-31 serum levels with severity of atopic dermatitis. J Allergy Clin Immunol 2008;122:421423.

50 Ezzat MH, Hasan ZE, Shaheen KY: Serum measurement of interleukin-31 (IL-31) in paediatric atopic dermatitis: elevated levels correlate with severity scoring. J Eur Acad Dermatol Venereol 2011;25:334-339.

51 Cheon BR, Shin JE, Kim YJ, Shim JW, Kim DS, Jung HL, et al: Relationship between serum 25-hydroxyvitamin $\mathrm{D}$ and interleukin-31 levels, and the severity of atopic dermatitis in children. Korean J Pediatr 2015;58: 96-101.

52 Mollanazar NK, Smith PK, Yosipovitch G: Mediators of chronic pruritus in atopic dermatitis: getting the itch out? Clin Rev Allergy Immunol 2016;51:263-292.

53 Castellani ML, Salini V, Frydas S, Donelan J, Madhappan B, Petrarca C, et al: Interleukin-31: a new cytokine involved in inflammation of the skin. Int J Immunopathol Pharmacol 2006; 19:1-4.

54 Grimstad O, Sawanobori Y, Vestergaard C, Bilsborough J, Olsen UB, Gronhoj-Larsen C, et al: Anti-interleukin-31-antibodies ameliorate scratching behaviour in NC/Nga mice: a model of atopic dermatitis. Exp Dermatol 2009; 18:35-43.

55 Sonkoly E, Muller A, Lauerma AI, Pivarcsi A, Soto H, Kemeny L, et al: IL-31: a new link between $\mathrm{T}$ cells and pruritus in atopic skin inflammation. J Allergy Clin Immunol 2006; 117:411-417.

56 Heise R, Neis MM, Marquardt Y, Joussen S, Heinrich PC, Merk HF, et al: IL-31 receptor alpha expression in epidermal keratinocytes is modulated by cell differentiation and interferon gamma. J Invest Dermatol 2009;129: 240-243.

57 Nemoto O, Furue M, Nakagawa H, Shiramoto $M$, Hanada R, Matsuki S, et al: The first trial of CIM331, a humanized antihuman interleukin-31 receptor A antibody, in healthy volunteers and patients with atopic dermatitis to evaluate safety, tolerability and pharmacokinetics of a single dose in a randomized, double-blind, placebo-controlled study. Br J Dermatol 2016;174:296-304.

58 Ruzicka T, Hanifin JM, Furue M, Pulka G, Mlynarczyk I, Wollenberg A, et al: Anti-interleukin-31 receptor $A$ antibody for atopic dermatitis. N Engl J Med 2017;376:826-835.

59 Soumelis V, Reche PA, Kanzler H, Yuan W, Edward G, Homey B, et al: Human epithelial cells trigger dendritic cell mediated allergic inflammation by producing TSLP. Nat Immunol 2002;3:673-680. 
60 Sano Y, Masuda K, Tamagawa-Mineoka R, Matsunaka H, Murakami Y, Yamashita R, et al: Thymic stromal lymphopoietin expression is increased in the horny layer of patients with atopic dermatitis. Clin Exp Immunol 2013; 171:330-337.

61 Dajnoki Z, Beke G, Mocsai G, Kapitany A, Gaspar K, Hajdu K, et al: Immune-mediated skin inflammation is similar in severe atopic dermatitis patients with or without filaggrin mutation. Acta Derm Venereol 2016;96:645650.

62 Angelova-Fischer I, Fernandez IM, Donnadieu MH, Bulfone-Paus S, Zillikens D, Fischer $\mathrm{TW}$, et al: Injury to the stratum corneum induces in vivo expression of human thymic stromal lymphopoietin in the epidermis. J Invest Dermatol 2010;130:2505-2507.

63 Vu AT, Baba T, Chen X, Le TA, Kinoshita H, Xie Y, et al: Staphylococcus aureus membrane and diacylated lipopeptide induce thymic stromal lymphopoietin in keratinocytes through the Toll-like receptor 2-Toll-like receptor 6 pathway. J Allergy Clin Immunol 2010;126:985-993, e981-e983.

64 Nakamura K, Tsuchida T, Tsunemi Y, Saeki H, Tamaki K: Serum thymic stromal lymphopoietin levels are not elevated in patients with atopic dermatitis. J Dermatol 2008;35:546547.

65 Lee EB, Kim KW, Hong JY, Jee HM, Sohn $\mathrm{MH}$, Kim KE: Increased serum thymic stromal lymphopoietin in children with atopic dermatitis. Pediatr Allergy Immunol 2010; 21:e457-e460.

66 Jariwala SP, Abrams E, Benson A, Fodeman J, Zheng T: The role of thymic stromal lymphopoietin in the immunopathogenesis of atopic dermatitis. Clin Exp Allergy 2011;41:15151520.

67 Ito T, Wang YH, Duramad O, Hori T, Delespesse GJ, Watanabe N, et al: TSLP-activated dendritic cells induce an inflammatory $\mathrm{T}$ helper type 2 cell response through OX40 ligand. J Exp Med 2005;202:1213-1223.

68 Gramaglia I, Jember A, Pippig SD, Weinberg AD, Killeen N, Croft M: The OX40 costimulatory receptor determines the development of CD4 memory by regulating primary clonal expansion. J Immunol 2000;165:3043-3050.

69 Ishii N, Takahashi T, Soroosh P, Sugamura K: OX40-OX40 ligand interaction in T-cell-mediated immunity and immunopathology. Adv Immunol 2010;105:63-98.

70 Lei W, Zhu $\mathrm{CH}$, Zeng da X, Wang Q, Zhang $\mathrm{XQ}$, Chen YB, et al. SOX40L: an important inflammatory mediator in adult bronchial asthma. Ann Acad Med Singapore 2012;41: 200-204.

71 Verstraete K, Peelman F, Braun H, Lopez J, Van Rompaey D, Dansercoer A, et al: Structure and antagonism of the receptor complex mediated by human TSLP in allergy and asthma. Nat Commun 2017;8:14937.
72 Gauvreau GM, O’Byrne PM, Boulet LP, Wang Y, Cockcroft D, Bigler J, et al: Effects of an anti-TSLP antibody on allergen-induced asthmatic responses. N Engl J Med 2014;370: 2102-2110.

73 Moreno AS, McPhee R, Arruda LK, Howell MD: Targeting the $\mathrm{T}$ helper 2 inflammatory axis in atopic dermatitis. Int Arch Allergy Immunol 2016;171:71-80.

74 Bao L, Zhang H, Chan LS: The involvement of the JAK-STAT signaling pathway in chronic inflammatory skin disease atopic dermatitis. JAKSTAT 2013;2:e24137.

75 Vestergaard C, Deleuran M, Gesser B, Gronhoj Larsen C: Expression of the T-helper 2-specific chemokine receptor CCR4 on CCR10-positive lymphocytes in atopic dermatitis skin but not in psoriasis skin. Br J Dermatol 2003;149:457-463.

76 Vestergaard C, Deleuran M, Gesser B, Larsen CG: Thymus- and activation-regulated chemokine (TARC/CCL17) induces a Th2-dominated inflammatory reaction on intradermal injection in mice. Exp Dermatol 2004;13:265271.

77 Thyssen JP, Kezic S: Causes of epidermal filaggrin reduction and their role in the pathogenesis of atopic dermatitis. J Allergy Clin Immunol 2014;134:792-799.

78 Nomura I, Goleva E, Howell MD, Hamid QA, Ong PY, Hall CF, et al: Cytokine milieu of atopic dermatitis, as compared to psoriasis, skin prevents induction of innate immune response genes. J Immunol 2003;171:32623269 .

79 O'Shea JJ, Plenge R: JAK and STAT signaling molecules in immunoregulation and immune-mediated disease. Immunity 2012;36: 542-550.

80 Levy LL, Urban J, King BA: Treatment of recalcitrant atopic dermatitis with the oral Janus kinase inhibitor tofacitinib citrate. J Am Acad Dermatol 2015;73:395-399.

81 Strand V, Lee EB, Fleischmann R, Alten RE, Koncz T, Zwillich SH, et al: Tofacitinib versus methotrexate in rheumatoid arthritis: patient-reported outcomes from the randomised phase III ORAL Start trial. RMD Open 2016;2:e000308.

82 Lee EB, Fleischmann R, Hall S, Wilkinson B, Bradley JD, Gruben D, et al: Tofacitinib versus methotrexate in rheumatoid arthritis. $\mathrm{N}$ Engl J Med 2014;370:2377-2386.

83 Genovese MC, Smolen JS, Weinblatt ME, Burmester GR, Meerwein S, Camp HS, et al: Efficacy and safety of ABT-494, a selective JAK-1 inhibitor, in a phase IIb study in patients with rheumatoid arthritis and an inadequate response to methotrexate. Arthritis Rheum 2016;68:2857-2866.

84 Sandborn WJ, Feagan B, Panes J: Safety and efficacy of ABT-494, an oral JAK1 inhibitor, as induction therapy in patients with Crohn's disease: results from CELEST (presentation 874). Digestive Disease Week, Chicago, May 6-9, 2017.
85 Dastidar SG, Rajagopal D, Ray A: Therapeutic benefit of PDE4 inhibitors in inflammatory diseases. Curr Opin Investig Drugs 2007;8: 364-372.

86 Hanifin JM, Chan SC, Cheng JB, Tofte SJ, Henderson WR Jr, Kirby DS, et al: Type 4 phosphodiesterase inhibitors have clinical and in vitro anti-inflammatory effects in atopic dermatitis. J Invest Dermatol 1996;107: 51-56.

87 Grewe SR, Chan SC, Hanifin JM: Elevated leukocyte cyclic AMP-phosphodiesterase in atopic disease: a possible mechanism for $\mathrm{cy}$ clic AMP-agonist hyporesponsiveness. J Allergy Clin Immunol 1982;70:452-457.

88 Baumer W, Hoppmann J, Rundfeldt C, Kietzmann M: Highly selective phosphodiesterase 4 inhibitors for the treatment of allergic skin diseases and psoriasis. Inflamm Allergy Drug Targets 2007;6:17-26.

89 Samrao A, Berry TM, Goreshi R, Simpson EL: A pilot study of an oral phosphodiesterase inhibitor (apremilast) for atopic dermatitis in adults. Arch Dermatol 2012;148:890-897.

90 Volf EM, Au SC, Dumont N, Scheinman P, Gottlieb AB: A phase 2, open-label, investigator-initiated study to evaluate the safety and efficacy of apremilast in subjects with recalcitrant allergic contact or atopic dermatitis. J Drugs Dermatol 2012;11:341-346.

91 Mathiesen JM, Christopoulos A, Ulven T, Royer JF, Campillo M, Heinemann A, et al: On the mechanism of interaction of potent surmountable and insurmountable antagonists with the prostaglandin $\mathrm{D}_{2}$ receptor CRTH2. Mol Pharmacol 2006;69:1441-1453.

92 Townley RG, Agrawal S: CRTH2 antagonists in the treatment of allergic responses involving $\mathrm{TH} 2$ cells, basophils, and eosinophils. Ann Allergy Asthma Immunol 2012;109: 365-374.

93 Helgason CD, Damen JE, Rosten P, Grewal R, Sorensen P, Chappel SM, et al: Targeted disruption of SHIP leads to hemopoietic perturbations, lung pathology, and a shortened life span. Genes Dev 1998;12:1610-1620.

94 Ong CJ, Ming-Lum A, Nodwell M, Ghanipour A, Yang L, Williams DE, et al: Smallmolecule agonists of SHIP1 inhibit the phosphoinositide 3-kinase pathway in hematopoietic cells. Blood 2007;110:1942-1949.

95 Aquinox Pharmaceuticals announces results from phase 2 KINSHIP trial with AQX-1125 in patients with atopic dermatitis. 2015. http://investor.aqxpharma.com/releasedetail.cfm?releaseid=939954.

96 Eyerich S, Eyerich K, Pennino D, Carbone T, Nasorri F, Pallotta S, et al: Th22 cells represent a distinct human $T$ cell subset involved in epidermal immunity and remodeling. J Clin Invest 2009;119:3573-3585. 
97 Czarnowicki T, Gonzalez J, Shemer A, Malajian $\mathrm{D}, \mathrm{Xu} \mathrm{H}$, Zheng $\mathrm{X}$, et al: Severe atopic dermatitis is characterized by selective expansion of circulating $\mathrm{TH} 2 / \mathrm{TC} 2$ and $\mathrm{TH} 22 /$ TC22, but not TH17/TC17, cells within the skin-homing T-cell population. J Allergy Clin Immunol 2015;136:104-115.e7.

98 Wolk K, Kunz S, Witte E, Friedrich M, Asadullah K, Sabat R: IL-22 increases the innate immunity of tissues. Immunity 2004;21: 241-254.

99 Gutowska-Owsiak D, Schaupp AL, Salimi M, Taylor S, Ogg GS: Interleukin-22 downregulates filaggrin expression and affects expression of profilaggrin processing enzymes. Br J Dermatol 2011;165:492-498.

100 Sabat R, Ouyang W, Wolk K: Therapeutic opportunities of the IL-22-IL-22R1 system. Nat Rev Drug Discov 2014;13:21-38.

101 Jenerowicz D, Czarnecka-Operacz M, Silny W: Peripheral blood eosinophilia in atopic dermatitis. Acta Dermatovenerol Alp Pannonica Adriat 2007;16:47-52.

102 Kiehl P, Falkenberg K, Vogelbruch M, Kapp A: Tissue eosinophilia in acute and chronic atopic dermatitis: a morphometric approach using quantitative image analysis of immunostaining. Br J Dermatol 2001;145:720729.

103 Dubucquoi S, Desreumaux P, Janin A, Klein O, Goldman M, Tavernier J, et al: Interleukin 5 synthesis by eosinophils: association with granules and immunoglobulin-dependent secretion. J Exp Med 1994;179:703708.

104 Corren J: Inhibition of interleukin-5 for the treatment of eosinophilic diseases. Discov Med 2012;13:305-312.

105 Mukherjee M, Sehmi R, Nair P: Anti-IL5 therapy for asthma and beyond. World Allergy Organ J 2014;7:32.
106 Oldhoff JM, Darsow U, Werfel T, Katzer K, Wulf A, Laifaoui J, et al: Anti-IL-5 recombinant humanized monoclonal antibody (mepolizumab) for the treatment of atopic dermatitis. Allergy 2005;60:693-696.

107 Nair P: Anti-interleukin-5 monoclonal antibody to treat severe eosinophilic asthma. N Engl J Med 2014;371:1249-1251.

108 Chapman BP, Moynihan J: The brain-skin connection: role of psychosocial factors and neuropeptides in psoriasis. Expert Rev Clin Immunol 2009;5:623-627.

109 Reich A, Szepietowski JC: Non-analgesic effects of opioids: peripheral opioid receptors as promising targets for future anti-pruritic therapies. Curr Pharm Des 2012;18:60216024.

110 Gerard NP, Garraway LA, Eddy RL Jr, Shows TB, Iijima H, Paquet JL, et al: Human substance $\mathrm{P}$ receptor (NK-1): organization of the gene, chromosome localization, and functional expression of cDNA clones. Biochemistry 1991;30:10640-10646.

111 Hon KL, Lam MC, Wong KY, Leung TF, Ng PC: Pathophysiology of nocturnal scratching in childhood atopic dermatitis: the role of brain-derived neurotrophic factor and substance P. Br J Dermatol 2007;157:922925.

112 Toyoda M, Nakamura M, Makino T, Hino T, Kagoura M, Morohashi M: Nerve growth factor and substance P are useful plasma markers of disease activity in atopic dermatitis. Br J Dermatol 2002;147:71-79.

113 Stander S, Weisshaar E, Luger TA: Neurophysiological and neurochemical basis of modern pruritus treatment. Exp Dermatol 2008; 17:161-169.

114 Stander S, Siepmann D, Herrgott I, Sunderkotter C, Luger TA: Targeting the neurokinin receptor 1 with aprepitant: a novel antipruritic strategy. PLoS One 2010;5:e10968.

115 Vanda Pharmaceuticals announces tradipitant phase II proof of concept study results for chronic pruritus in atopic dermatitis: PR newswire. 2015. https://goo.gl/7OQxsM.
116 Jancin B: Promising pipeline for chronic pruritus: MDedge. 2017. https://goo.gl/xM1TOc.

117 Schulman ES: Development of a monoclonal anti-immunoglobulin E antibody (omalizumab) for the treatment of allergic respiratory disorders. Am J Respir Crit Care Med 2001;164:S6-S11.

118 Chang TW, Shiung YY: Anti-IgE as a mast cell-stabilizing therapeutic agent. J Allergy Clin Immunol 2006;117:1203-1212; quiz 1213.

119 Heil PM, Maurer D, Klein B, Hultsch T, Stingl G: Omalizumab therapy in atopic dermatitis: depletion of IgE does not improve the clinical course - a randomized, placebocontrolled and double blind pilot study. J Dtsch Dermatol Ges 2010;8:990-998.

120 Krathen RA, Hsu S: Failure of omalizumab for treatment of severe adult atopic dermatitis. J Am Acad Dermatol 2005;53:338-340.

121 Vigo PG, Girgis KR, Pfuetze BL, Critchlow ME, Fisher J, Hussain I: Efficacy of anti-IgE therapy in patients with atopic dermatitis. J Am Acad Dermatol 2006;55:168-170.

122 Kim DH, Park KY, Kim BJ, Kim MN, Mun SK: Anti-immunoglobulin $\mathrm{E}$ in the treatment of refractory atopic dermatitis. Clin Exp Dermatol 2013;38:496-500.

123 Lane JE, Cheyney JM, Lane TN, Kent DE, Cohen DJ: Treatment of recalcitrant atopic dermatitis with omalizumab. J Am Acad Dermatol 2006;54:68-72.

124 Arm JP, Bottoli I, Skerjanec A, Floch D, Groenewegen A, Maahs S, et al: Pharmacokinetics, pharmacodynamics and safety of QGE031 (ligelizumab), a novel high-affinity anti-IgE antibody, in atopic subjects. Clin Exp Allergy 2014;44:1371-1385. 